\title{
Research on Volatile Organic
} Compounds From Bacillus subtilis CF-3: Biocontrol Effects on Fruit Fungal Pathogens and Dynamic Changes During Fermentation

\author{
Haiyan Gao ${ }^{1,2 *}$, Peizhong $L^{1,2}{ }^{1,2}$ Xinxing $X u^{1,2}$, Qing Zeng ${ }^{1,2}$ and Wenqiang Guan ${ }^{3 *}$ \\ ${ }^{1}$ School of Life Sciences, Shanghai University, Shanghai, China, ${ }^{2}$ Shanghai Key Laboratory of Bio-Energy Crops, Shanghai, \\ China, ${ }^{3}$ Tianjin Key Laboratory of Food Biotechnology, College of Biotechnology and Food Science, Tianjin University of \\ Commerce, Tianjin, China
}

OPEN ACCESS

Edited by:

Rosalba Lanciotti,

Università di Bologna, Italy

Reviewed by:

Eliana Barreto-Bergter,

Universidade Federal do Estado do

Rio de Janeiro, Brazil

Maurice Ndagijimana,

University of Alberta, Canada

Rosanna Tofalo,

Università di Teramo, Italy

*Correspondence:

Haiyan Gao

hygao1111@126.com

Wenqiang Guan

gwq18@163.com

Specialty section

This article was submitted to

Food Microbiology,

a section of the journal

Frontiers in Microbiology

Received: 06 September 2017

Accepted: 27 February 2018

Published: 14 March 2018

Citation:

Gao H, Li P, Xu X, Zeng Q and Guan W (2018) Research on Volatile Organic Compounds From Bacillus subtilis CF-3: Biocontrol Effects on Fruit Fungal Pathogens and Dynamic

Changes During Fermentation.

Front. Microbiol. 9:456.

doi: 10.3389/fmicb.2018.00456
The dynamic changes of the levels of volatile organic compounds (VOCs) produced by Bacillus subtilis CF-3 and their biocontrol effects on common fungal pathogens were researched in this study. The results showed that the VOCs in 24-h fermentation liquid (24hFL) of B. subtilis CF-3 inhibited mycelial growth of Botrytis cinerea, Colletotrichum gloeosporioides, Penicillium expansum, Monilinia fructicola, and Alternaria alternata, with a mean inhibition rate of $59.97 \%$. The inhibitory effect on $M$. fructicola and C. gloeosporioides was the highest; they were therefore selected as target fungal pathogens for further experiments. Based on headspace solid-phase microextraction combined with gas chromatography-mass spectrometry (HS-SPME-GC-MS), 74 potential VOCs were identified during the fermentation: 15 alcohols, 18 ketones, 4 pyrazines, 4 esters, 10 acids, 5 phenols, 3 hydrocarbons, 3 amines, 2 aldehydes, 5 ethers, and 5 other components. At different fermentation times, the type and content of VOCs were different. Most of the potential VOCs (62 VOCs) were identified in the 48hFL. The inhibition rates of all VOCs reached their peaks (73.46\% on M. fructicola and $63.63 \%$ on C. gloeosporioides) in the 24hFL. Among the identified VOCs, 2,4-di-tert-butylphenol, 1-octanol, and benzothiazole showed significant positive correlations with the rates of $M$. fructicola and C. gloeosporioides inhibition. Benzoic acid and benzaldehyde showed a significant positive correlation with the rates of $M$. fructicola inhibition, and anisole and 3-methylbutanal showed a significant positive correlation with the rates of C. gloeosporioides inhibition. In vitro, 2,4-di-tert-butylphenol showed a strong inhibitory effect on both $M$. fructicola and C. gloeosporioides. In vivo, benzothiazole showed the strongest inhibitory effect on the mycelial extensions of both $M$. fructicola and C. gloeosporioides, which also led to an increased rate of healthy fruit. The results of the present study clarified that 2,4-di-tert-butylthiophenol and benzothiazole are key inhibitory VOCs produced by B. subtilis CF-3.

Keywords: Bacillus subtilis, volatile organic compounds (VOCs), biocontrol, fruit fungal pathogens, Monilinia fructicola, Colletotrichum gloeosporioides 


\section{INTRODUCTION}

Postharvest decay caused by fungal pathogens is one of the main factors limiting the storage life of fruit, and it results in substantial economic losses, especially in the fruit market supply chain (Prusky, 2011). The control of postharvest fruit diseases formerly depended on cold or controlled atmosphere storage and fungicides (Zheng et al., 2013). Fungicides are widely used to limit postharvest decay and extend the shelflife of fruit. However, they are becoming less effective, owing to the development of pathogen resistance, which results in the overuse and misuse of fungicides and causes a public health risk (Schreinemachers and Tipraqsa, 2012). Despite these problems, fungicides are currently essential for ensuring that the food supply meets the demands of the increasing global population (Wang and Liu, 2007). Therefore, alternative methods are needed to address the concerns related to global environmental contamination and human health risks caused by fungicide residues.

The use of biocontrol microorganisms is a promising strategy for the control of postharvest diseases (Zheng et al., 2013). Many antagonistic microorganisms, e.g., Aureobasidium pullulans (Mari et al., 2012), Metschnikowia fructicola (Banani et al., 2015), and Bacillus amyloliquefaciens (Arrebola et al., 2010), exhibit biocontrol activity that can control the growth of postharvest fungal pathogens on fruit. Among these common biocontrol microorganisms, Bacillus subtilis is widely used in agricultural biocontrol applications and to promote plant growth (Ma et al., 2015). Previous studies have indicated that B. subtilis can inhibit the mycelial growth of many fungal pathogens (Chen et al., 2008; Leelasuphakul et al., 2008), including Penicillium expansum (Senthil et al., 2011), Monilinia fructicola (Casals et al., 2012), and Botrytis cinerea (Maachia et al., 2015). B. subtilis produces a number of antifungal compounds that have important functions in biocontrol, such as lipopeptides (e.g., surfactin, iturin, and fengycin) (Torres et al., 2016) and antifungal enzymes [e.g., chitinase (Liu et al., 2011) and chitosanase (Wang and Yeh, 2008)].

However, while most previous studies have focused on the antifungal proteins of $B$. subtilis, little is known about its volatile organic compounds (VOCs). Recently, VOCs produced by $B$. subtilis have been proposed as an alternative control method for postharvest fruit diseases (Zheng et al., 2013) because they can inhibit the mycelial growth and spore germination of various pathogenic fungi (Chen et al., 2008). For instance, various VOCs (e.g., 2-nonanone, 2-methylpyrazine, and $\beta$ benzeneethanamine) produced by $B$. subtilis TB09 and TB72 effectively controlled the anthracnose pathogen on postharvest mangoes (Zheng et al., 2013), and VOCs produced by B. subtilis PPCB001 inhibited growth of Penicillium crustosum by over $50 \%$, reducing postharvest decay in citrus fruits (Arrebola et al., 2010).

Research into the VOCs produced by B. subtilis has thus far primarily focused on identifying exact VOC components and evaluating their biocontrol effects. However, research into dynamic changes in VOCs during microbial fermentation and their biocontrol effects is still scarce. Because the activity and metabolic capacity of a biocontrol strain, as well as the types of
VOCs secreted, may change during fermentation (Wang et al., 2016), it is necessary to study the dynamic change in VOCs and biocontrol activity during fermentation in order to determine which compounds play the most important roles in pathogen inhibition.

In a previous study, we isolated, identified, and named the B. subtilis strain CF-3, which exhibited biocontrol effects (Gao et al., 2016). Moreover, the VOCs produced by B. subtilis CF3 were also identified after $48 \mathrm{~h}$ of cultivation (Gao H. Y. et al., 2017). Considering these findings, the objectives of the present study were: (1) to evaluate the antifungal spectrum and inhibitory effects of VOCs produced by B. subtilis CF-3 on common fungal pathogens in vitro; (2) to identify the dynamic changes in the levels of VOCs secreted by B. subtilis CF-3 during fermentation using headspace solid-phase micro-extraction combined with gas chromatography-mass spectrometry (HS-SPME-GC-MS); (3) to discover the correlation between compounds and inhibition rates by evaluating the dynamic inhibition rates of VOCs secreted from B. subtilis CF-3; and (4) to ascertain which compounds were key factors in the inhibition of fungal pathogens both in vivo and in vitro.

\section{MATERIALS AND METHODS}

\section{Bacillus Strain}

Bacillus subtilis CF-3 (registered in the China Center for Type Culture Collection, CCTCC M 2016125) was isolated from fermented bean curd and identified by the Laboratory of Food Safety and Quality Control (School of Life Sciences, Shanghai University) (Gao et al., 2016). For short-term storage, B. subtilis CF-3 was incubated at $37^{\circ} \mathrm{C}$ for $24 \mathrm{~h}$ on Luria-Bertani (LB) agar (Gao H. Y. et al., 2017). All chemicals used were purchased from Sinopharm Chemical Reagent Co., Ltd. (Shanghai, China).

\section{Pathogenic Fungi}

The following common fungal pathogens of fruit were selected for this study: Botrytis cinerea, responsible for gray mold on strawberries and tomatoes (Wang et al., 2013; Ugolini et al., 2014); Colletotrichum gloeosporioides, which causes anthracnose in litchis (Sivakumar et al., 2008); Penicillium expansum, responsible for blue mold on apples (Spadoni et al., 2015); Monilinia fructicola, which causes peach brown rot (Zhang et al., 2015); Alternaria alternata, which causes Alternaria rot and black spot on jujube (Yan et al., 2015); and Macrophoma kuwatsukai, which promotes ring rot in apples (Xu et al., 2015). A. alternata, B. cinerea, $M$. kuwatsukai, and $P$. expansum were provided by the College of Horticulture and Landscape, Tianjin Agricultural University; C. gloeosporioides was provided by the Chinese Academy of Tropical Agricultural Sciences Environment and Plant Protection Institute; and M. fructicola was provided by the Laboratory of Agricultural Products Processing and Storage, Food Science and Engineering College, Beijing University of Agriculture. They were plated onto potato dextrose agar (PDA) medium (Gao H. Y. et al., 2017) in Petri dishes $(\varnothing 90 \mathrm{~mm})$ and incubated at $28^{\circ} \mathrm{C}$ for 7 days prior to use. 


\section{Preparation of $B$. subtilis CF-3 Fractions}

After $24 \mathrm{~h}$ of incubation on LB agar, B. subtilis CF-3 was gently scraped and transferred into $100 \mathrm{~mL}$ of $\mathrm{LB}$ liquid medium in a conical flask and cultivated at $37^{\circ} \mathrm{C}$ in a rotary shaker at $150 \mathrm{rpm}$ for $24 \mathrm{~h}$. Subsequently, approximately $1 \times 10^{8}$ colony forming units $(\mathrm{CFU}) / \mathrm{mL}$ were counted using a hemocytometer. Afterwards, $4.15 \mathrm{~mL}$ of the prepared B. subtilis $\mathrm{CF}-3$ liquid was transferred into $41.5 \mathrm{~mL}$ of fresh culture solution, which was then sealed with a silicone pad and aluminum cap in a custom-made conical flask with side arms bound with eight layers of sterile gauze (Gao H. Y. et al., 2017). Eight such conical flasks were prepared and placed in a 150 -rpm rotary shaker at $37^{\circ} \mathrm{C}$ for 12-96 h: the flasks were taken out one by one at 12-h intervals, i.e., at 12,24 , and $36 \mathrm{~h}$, and so forth. The fermentation liquid obtained after shaking the flask cultivated for $12 \mathrm{~h}$ was termed the 12 -h cultivated fermentation liquid ( $12 \mathrm{hFL})$, and the remaining fermentation liquids were named in the same manner $(24 \mathrm{hFL}$, $36 \mathrm{hFL}$, and so forth). The cell-free filtrate (CFF) of B. subtilis CF3 from the $24 \mathrm{hFL}$ was obtained using the method reported by Jiang et al. (2014). A bacterial suspension (BS) of B. subtilis CF3 was obtained from by diluting the bacterial pellet obtained by centrifugation of the $24 \mathrm{hFL}$ with tryptone-buffered saline (TPS; $1 \mathrm{~g}$ tryptone and $8.5 \mathrm{~g} \mathrm{NaCl}$, diluted with distilled sterile water to $1 \mathrm{~L}, \mathrm{pH}=7.0$ ), and the cell concentration was adjusted to the approximate cell concentration of the $24 \mathrm{hFL}$. The CFF and BS were selected to explore whether the bacterium or its secretions have a stronger inhibitory effect on the fungi.

\section{Fruit Preparation}

Peaches (Prunus persica cv. DaJiubao) and litchi (Litchi chinensis Sonn.) were harvested in orchards in the Shandong and Guangxi provinces, China, respectively. After being harvested and transported to the laboratory, the fruits were processed immediately. Fruits were selected based on size uniformity, ripeness, and the absence of visual injuries or infections. Subsequently, they were superficially disinfected by immersion in $0.1 \%(\mathrm{v} / \mathrm{v})$ sodium hypochlorite for $1 \mathrm{~min}$, rinsed with tap water, and air-dried at room temperature $\left(25^{\circ} \mathrm{C}\right)$.

\section{Preparation of Spore Suspensions of Pathogenic Fungi}

Pathogenic fungi were prepared as spore suspensions by flushing the surface of the PDA medium containing Tween 80 diluted in distilled water to $0.05 \%(\mathrm{v} / \mathrm{v})$ that was used for cultivating the fungi for 7 days at $28^{\circ} \mathrm{C}$. The liquid was then filtered through eight layers of sterile cheesecloth, and the concentration was adjusted to $1 \times 10^{5}$ conidia/mL using distilled water.

\section{Inhibitory Effects of VOCs Produced by B. subtilis CF-3 on Pathogenic Fungi in Vitro}

The $24 \mathrm{hFL}, \mathrm{CFF}$ of the $24 \mathrm{hFL}$, and BS of the $24 \mathrm{hFL}$ of $B$. subtilis CF-3 were used as three treatments, and A. alternata, B. cinerea, $M$. kuwatsukai, P. expansum, C. gloeosporioides, and M. fructicola were selected as the target pathogenic fungi for the experiments. The inhibition rate was evaluated by mycelial growth of the fungi. The inhibitory effects of VOCs produced by fermentation and the components of the fermentation liquids of $B$. subtilis CF-3 were evaluated using the methods described by Arrebola et al. (2010). In brief, LB agar plates $(\varnothing 90 \mathrm{~mm})$ were uniformly coated with $20 \mu \mathrm{L}$ of the $24 \mathrm{hFL}$, CFF of the $24 \mathrm{hFL}$, or BS of the $24 \mathrm{hFL}$. Subsequently, a plug $(\varnothing 7 \mathrm{~mm})$ from the agar of each of the fungi, which were incubated for 7 days, was punched and separately placed at the center of a fresh PDA medium. Then, a Petri dish "sandwich" was made (Jiang et al., 2014) using the PDA medium inoculated with a pathogenic fungus on the bottom and a $B$. subtilis CF-3 liquid-coated LB agar medium on the top. The set of two plates was sealed with parafilm and incubated at $28^{\circ} \mathrm{C}$. LB plates coated with distilled water (for fermentation liquids and CFF of the 24hFL) or TPS (for BS of the $24 \mathrm{hFL}$ ) were used as negative controls. The mycelial diameter $(\mathrm{mm})$ of the fungi was measured after 7 days. There were three replicates for each treatment, and the experiment was repeated three times.

The inhibition rate of mycelial growth in vitro (R) was calculated using the equation:

$$
R(\%)=\frac{D_{1}-D_{2}}{D_{1}-D_{0}} \times 100
$$

where $R$ is the percent of inhibition of mycelial extension; $D_{1}$ is the mycelial diameter $(\mathrm{mm})$ of the negative control set; $D_{2}$ is the mycelial diameter of the treated set, including the size of the fungal agar plug $(\mathrm{mm})$; and $D_{0}$ is the original mycelial diameter $(\varnothing 7 \mathrm{~mm})$ of the punched fungal agar plug.

\section{HS-SPME-GC-MS Analysis of the Dynamic Change of VOCs From B. subtilis CF-3 During Fermentation and GC-MS Conditions}

We analyzed the VOCs in the fermentation liquids (from the $12 \mathrm{hFL}$ to the 96hFL) of B. subtilis CF-3. Peak area was used to evaluate the dynamic quantitative changes of VOCs during fermentation. The conical flasks loaded with the fermentation liquid were taken out one by one in 12-h intervals and prepared for the extraction process. The flasks were sealed with silicone septa and aluminum caps, placed in a temperaturecontrolled water bath for $30 \mathrm{~min}$ at $30^{\circ} \mathrm{C}$ to equilibrate, and then maintained in water baths at $39^{\circ} \mathrm{C}$. To extract VOCs secreted by $B$. subtilis CF-3, three different kinds of extraction fibers were used: $85-\mu \mathrm{m}$ polyacrylate (PA; Supelco, Bellefonte, PA, USA) fiber for extracting strongly polar compounds, $100-\mu \mathrm{m}$ polydimethylsiloxane (PDMS; Supelco) fiber for extracting lowmolecular weight VOCs, and 7- $\mu$ m PDMS (Supelco) fiber for extracting high-molecular weight VOCs. Before analysis, the fibers were preconditioned as follows: the $85-\mu \mathrm{m}$ PA fiber was heated at $280^{\circ} \mathrm{C}$ for $1 \mathrm{~h}$, the $100-\mu \mathrm{m}$ PDMS fiber was heated at $250^{\circ} \mathrm{C}$ for $30 \mathrm{~min}$, and the $7-\mu \mathrm{m}$ PDMS fiber was heated at $320^{\circ} \mathrm{C}$ for $1 \mathrm{~h}$. The fibers were inserted into the conical flasks through the silicone pads, fixed at about $1 \mathrm{~cm}$ above the surface of the liquid, and exposed to headspace for $41 \mathrm{~min}$ at $39^{\circ} \mathrm{C}$ to extract the VOCs. One flask of fresh LB liquid medium was used as a control and processed under the same conditions to eliminate the substances 
volatilized from the liquid medium. Subsequently, the fibers were removed from the flasks and immediately inserted into the injection port of the GC-MS apparatus for analysis. The GC-MS conditions and procedures were selected as previously described (Gao H. Y. et al., 2017): when one compound was identified by multiple extraction fibers simultaneously, the conditions that yielded the highest probability were adopted. Each fermentation liquid was analyzed in triplicate.

\section{Dynamic Change in Rates of Fungal Pathogen Inhibition by B. subtilis CF-3 VOCs During Fermentation in Vitro}

Fermentation liquids of $B$. subtilis CF-3 (from the 12hFL to the $96 \mathrm{hFL} ; 20 \mu \mathrm{L}$ ) were uniformly spread onto LB agar plates (Ø90 mm). Subsequently, a plug $(\varnothing 7 \mathrm{~mm})$ from the agar of each of the fungi, which were incubated for 7 days, was punched and placed onto the center of a fresh PDA plate. A sandwich was made, with the PDA medium with the fungi on the bottom and the B. subtilis CF-3 liquid-coated LB agar on the top. The set of two plates was sealed with parafilm and incubated at $28^{\circ} \mathrm{C}$. Plate sets of the fungal pathogen PDA medium on the bottom and the LB plate coated with distilled water on the top were used as negative controls and incubated under the same conditions. The mycelial diameter $(\mathrm{mm})$ of fungal pathogens was measured after 7 days. The inhibition rate was calculated by Equation 1. There were three replicates for each treatment, and the experiment was repeated three times.

\section{Evaluation of Inhibitory Effects of Single Identified VOCs on Fungal Pathogens in Vitro}

Compounds were selected based on the correlation between the dynamic change of peak area in one compound during fermentation and the dynamic inhibition rate of the VOCs from B. subtilis CF-3 on fungal pathogens during fermentation through bivariate correlation analysis, and those that showed significant $(P<0.05)$ positive correlations were selected for the subsequent experiments. The selected compounds (technical grade) were purchased from Sinopharm Chemical Reagent Co., Ltd. (Shanghai, China). The compounds were serially diluted six times by 10 -fold dilution in dimethyl sulfoxide. All purchased original reagents that were in solid state under normal conditions were dissolved in advance and diluted to $1 \mathrm{~mol} / \mathrm{L}$ using dimethyl sulfoxide. The mycelial inhibition rates of fungal pathogens were evaluated as the inhibition activity. The reagent liquid $(20 \mu \mathrm{L})$ was uniformly spread onto a water-agar plate (18 g agar diluted with distilled sterile water to $1 \mathrm{~L})$. Subsequently, plugs $(\varnothing 7 \mathrm{~mm})$ from the agars on which the fungi were incubated were punched and placed onto the center of fresh PDA media, and sandwiches of the two plates was sealed together with parafilm, as described previously. Water-agar plates not coated or coated with dimethyl sulfoxide were incubated and used as controls. The mycelial extension ( $\mathrm{mm}$ ) of the fungi was measured after 7 days. The inhibition rate of mycelial growth was calculated by Equation 1 . In addition, the half maximal effective concentration $\left(\mathrm{EC}_{50}\right)$ was calculated. There were three replicates for each treatment, and the experiment was repeated three times.

\section{Inhibitory Effects of Single Identified VOCs and the 24hFL of $B$. subtilis CF-3 on Fungal Pathogens in Vivo}

Two in vivo experiments on peaches and litchi fruit were performed. For the peaches, a uniform wound $(10 \mathrm{~mm}$ in diameter $\times 5 \mathrm{~mm}$ deep) was made at the equator of each peach using a sterilized puncher. Subsequently, a spore suspension of M. fructicola $(20 \mu \mathrm{L})$ was applied to the wound sites at the same depth and air-dried. For litchi fruit, a spore suspension

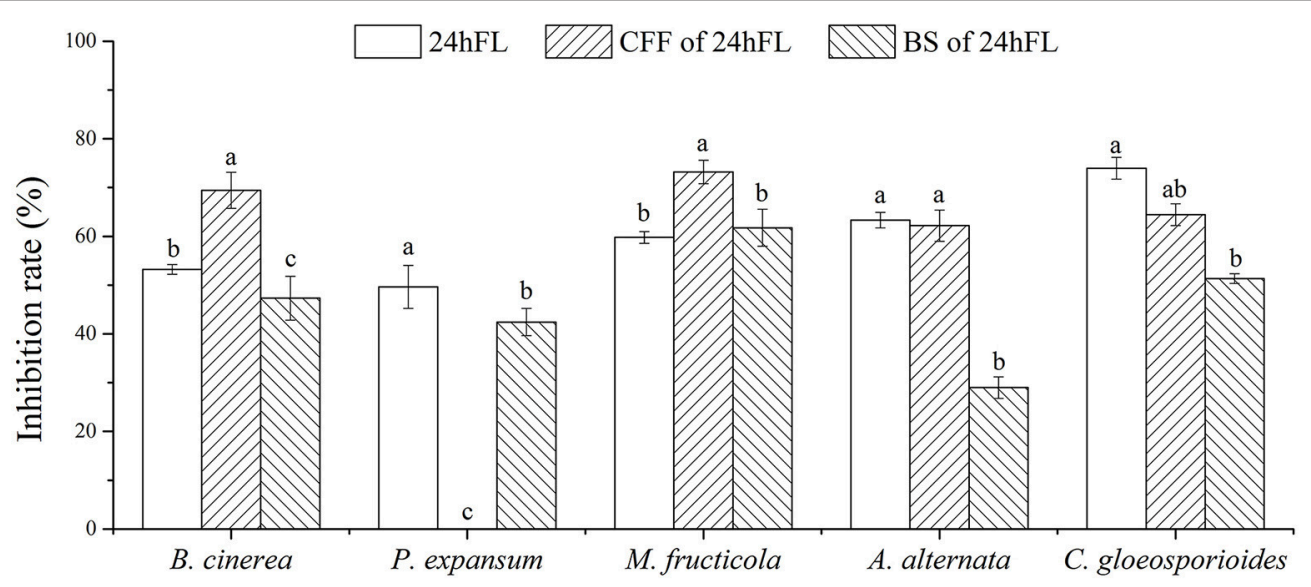

Fungal pathogen

FIGURE 1 | Inhibitory effects of VOCs from B. subtilis CF-3 fractions on fungal pathogens in vitro. "24hFL" indicates the 24-h fermentation liquid of B. subtilis CF-3, "CFF of $24 \mathrm{hFL}$ " indicates the cell-free filtrate of the $24-\mathrm{h}$ fermentation liquid of B. subtilis CF-3, and "BS of 24hFL" indicates the bacterial suspension of the 24-h fermentation liquid of $B$. subtilis CF-3. Each column represents the mean value from three independent experiments, and vertical bars represent the standard errors of the means for each treatment. Different letters represent significant differences $(P<0.05)$ in the inhibition rates between different treatments on the same fungi. 
of C. gloeosporioides $(20 \mu \mathrm{L})$ was directly injected into the flesh ( $2 \mathrm{~mm}$ deep) using a sterile syringe, and the fruit was air-dried. After inoculation, the fruits were placed on sterile plastic trays $(4 \times 3$ wells, each $400 \times 280 \mathrm{~mm}$; each well for 1 peach or 2 litchi fruit), and the first and the fourth well in the middle row were left empty for applying VOCs. Afterwards, two filter papers $(\varnothing 90 \mathrm{~mm})$ were placed onto the two empty wells, and $200 \mu \mathrm{L}$ of the original reagent liquid of each single identified VOCs or of the 24hFL of B. subtilis CF-3 was dripped onto filter paper. All purchased original reagents that were in solid state under normal conditions were dissolved in advance and diluted to $1 \mathrm{~mol} / \mathrm{L}$ using dimethyl sulfoxide. The trays were then put into a carton $(450 \times 350 \times 100 \mathrm{~mm})$. After being sealed, the carton was packed into polyethylene packaging bags and stored at room temperature $\left(25^{\circ} \mathrm{C}\right)$. Cartons with filter papers that were not soaked (negative control for original reagent liquid) or soaked with distilled water (negative control for the $24 \mathrm{hFL}$ of B. subtilis CF-3) or dimethyl sulfoxide (negative control for dissolved solid reagents) were also stored under the same conditions. The mycelial diameter $(\mathrm{mm})$ and healthy fruit rate (\%) were evaluated every day at the same time up to the fifth day after inoculation. Considering the instability of VOCs, the fruits were discarded after daily evaluation and new cartons were opened the next day. There were three replicates of 10 peaches and 20 litchi fruit for each treatment, and the experiment was repeated three times.

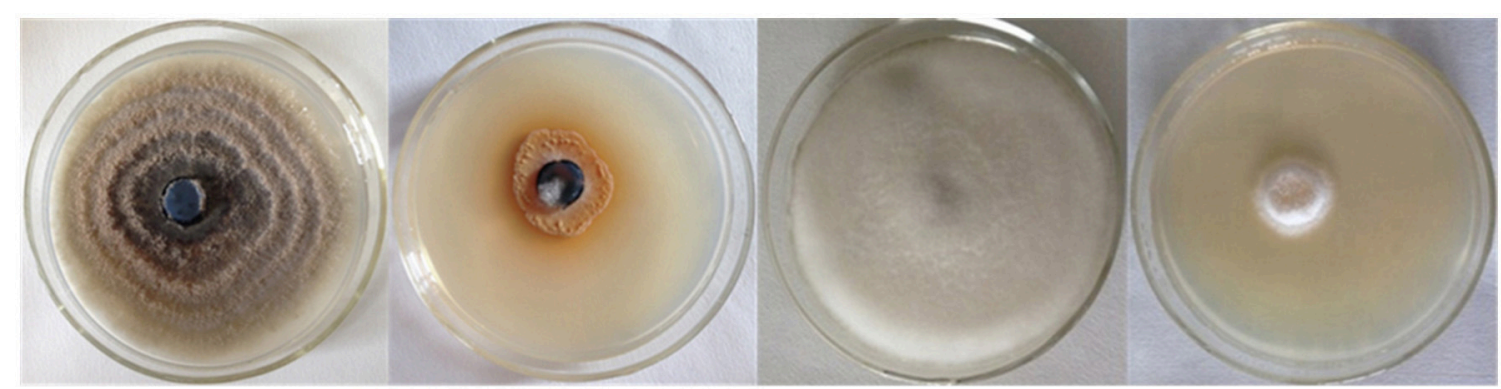
M. fructicola
M. fructicola
C. gloeosporioides
C. gloeosporioides
Control
VOCs exposed (24hFL)
Control
vOCs exposed (24hFL)

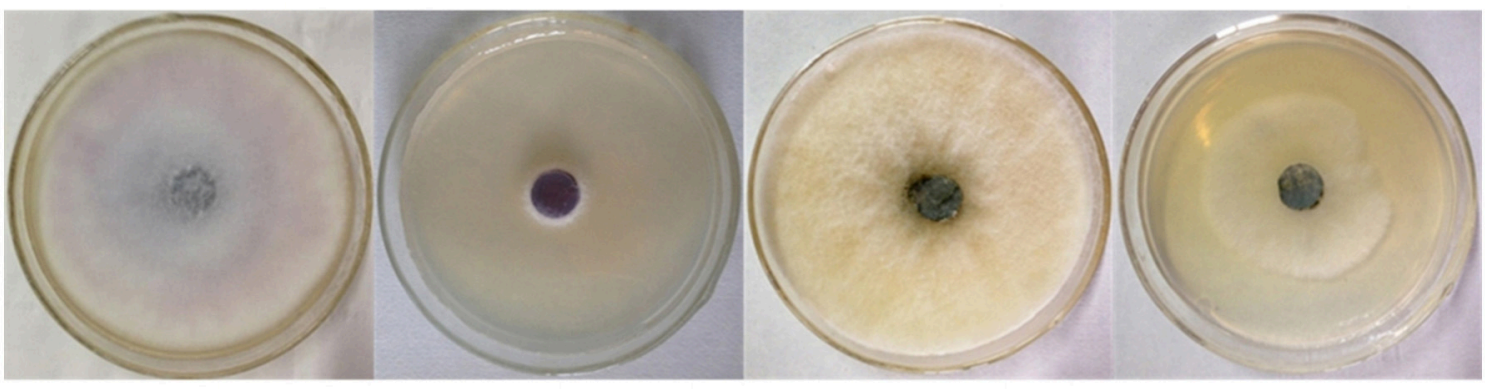

B. cinerea

B. cinerea

P. expansum

P. expansum

Control VOCs exposed (24hFL)

Control

VOCs exposed (24hFL)

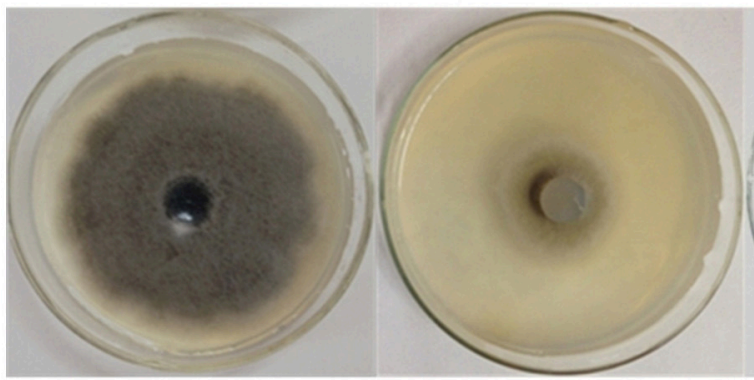

A. alternata

Control
A. alternata

VOCs exposed (24hFL)

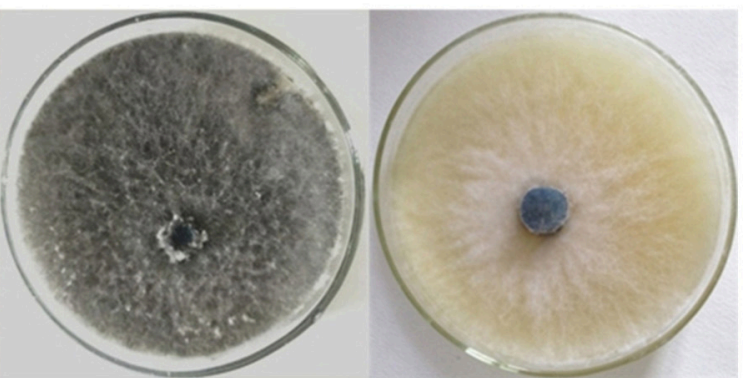

M. kuwatsukai

M. kuwatsukai

Control VOCs exposed (24hFL)

FIGURE 2 | Mycelial growth of common fruit fungal pathogens exposed to VOCs from 24-h fermentation liquid (24hFL) of B. subtilis CF-3 and control in vitro. 


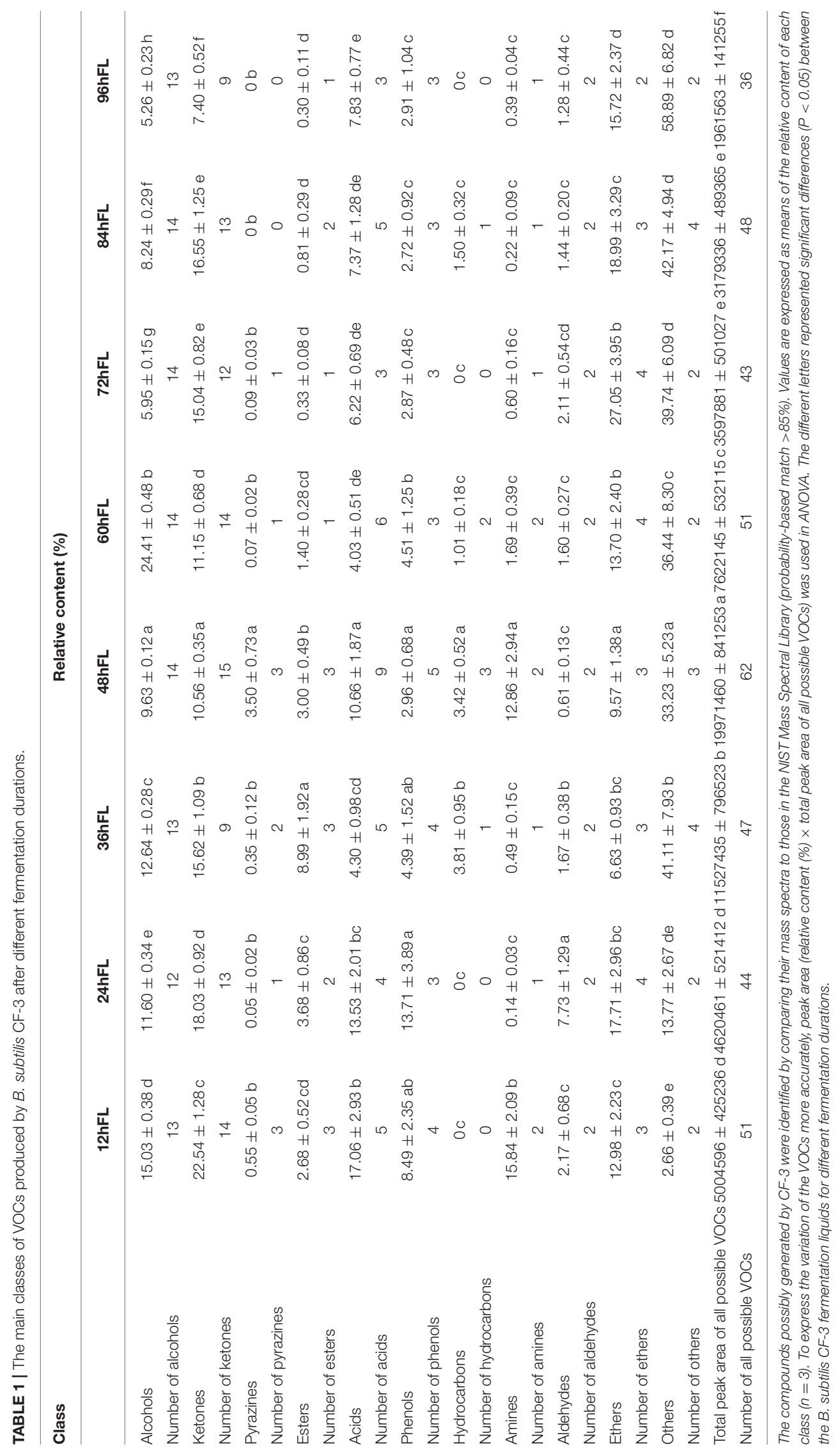


The inhibition rate of mycelial growth in vivo $\left(\mathrm{R}_{\mathrm{f}}\right)$ was calculated using the equation:

$$
R_{f}(\%)=\frac{D_{f 1}-D_{f 2}}{D_{f 1}} \times 100
$$

where $R_{f}$ is the percent of inhibition of mycelial extension, $D_{f 1}$ is the mycelial diameter $(\mathrm{mm})$ of the negative control set, and $D_{f 2}$ is the mycelial diameter $(\mathrm{mm})$ of the treated set.

\section{Statistical Analysis}

As one of the objectives of this study was to assess the dynamic change in VOCs, the differences in the volatile profiles during fermentation were analyzed using analysis of variance (ANOVA), using the SPSS 19.0 software (SPSS Inc., Chicago, IL, USA). Duncan's post-hoc test was applied to compare the mean values of the VOCs. A significance level of $P<0.05$ was used to determine the significant differences of the content of VOCs produced after different fermentation times. Mean values with standard deviations were reported.

Additionally, analysis of the correlations between the peak areas of identified VOCs and the inhibition rates was carried out by bivariate correlation analysis and calculated using the SPSS 19.0 software. The $\mathrm{EC}_{50}$ of single VOCs was calculated using GraphPad Prism 6.01 (GraphPad Software, Inc., La Jolla, CA, USA). All graphs were produced by Origin Pro 8.5 (OriginLab Corp., Northampton, MA, USA).

\section{RESULTS}

\section{Inhibitory Effects of VOCs Produced by $B$. subtilis CF-3 on Fungal Pathogens in Vitro}

To explore the biocontrol effects of VOCs produced by B. subtilis CF-3 on different common fungal pathogens, the inhibition rate of VOCs was evaluated in three different fractions: the 24hFL, CFF of the 24hFL, and BS of the 24hFL. The effects of VOCs from the $24 \mathrm{hFL}$ on M. fructicola and C. gloeosporioides had already been estimated in a previous study (Gao H. Y. et al., 2017). The results demonstrated that most of the treatments had strong antifungal abilities against most selected fungal pathogens except on M. kuwatsukai, which was not inhibited by any treatment. Additionally, P. expansum was not inhibited by the VOCs of the CFF of the 24hFL. As shown in Figures 1, 2 the antifungal effects depended on the pathogens and treatment. The VOCs of the $24 \mathrm{hFL}$ exhibited the highest mean inhibition rate against all tested fungal pathogens in all treatments (59.97\%), and the mean rates for the CFF and BS of the $24 \mathrm{hFL}$ were 53.84 and $46.36 \%$, respectively. In the present study, almost all collected fungal pathogens were inhibited, indicating that B. subtilis CF-3 has a relatively broad antifungal spectrum; thus, it is necessary to identify the key inhibitory VOCs produced by $B$. subtilis CF-3. Among the tested pathogens, M. fructicola was the most susceptible: the mean inhibition rate of the three treatments was 64.91\%. Furthermore, C. gloeosporioides was strongly inhibited, with a mean rate of $63.22 \%$. These two fungi are common fruit fungal pathogens (Munir et al., 2016; Fischer et al., 2017),

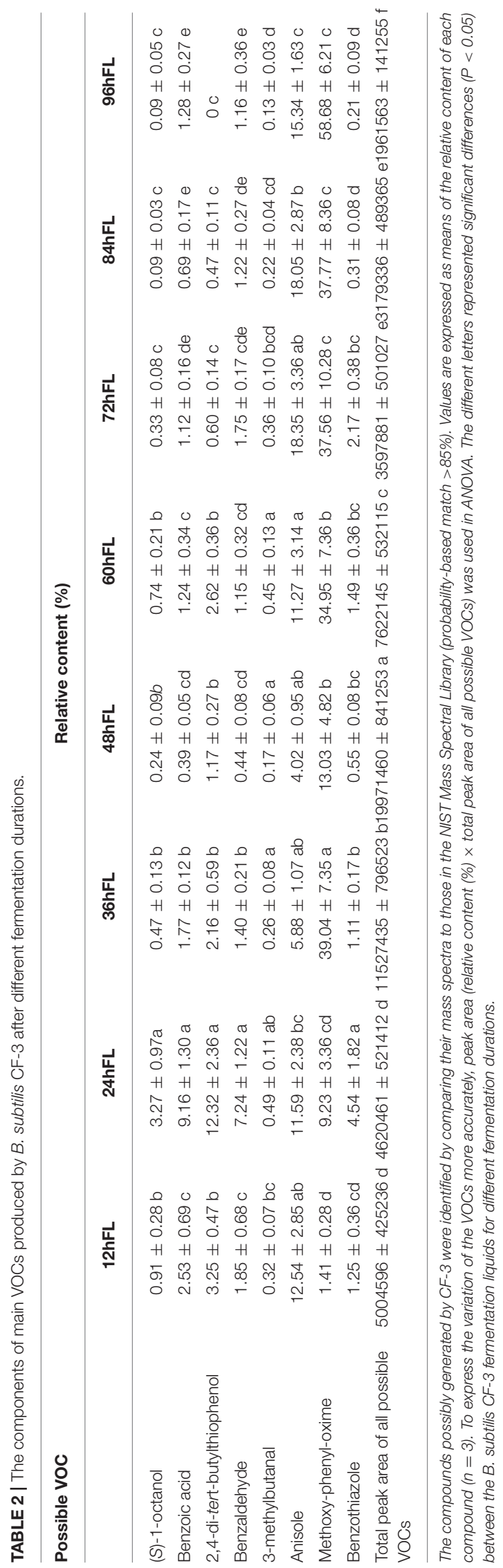


which is why they have been chosen as targets in the subsequent experiments.

\section{Changes in VOC Production at Different Fermentation Durations, Their Inhibitory Effects on M. fructicola and C. gloeosporioides, and the Correlation Between Them}

In this study, 74 different compounds volatilized in the liquids of B. subtilis CF-3 at different fermentation times were identified using HS-SPME-GC-MS (Table 1, Table S1): 15 alcohols, 18 ketones, 4 pyrazines, 4 esters, 10 acids, 5 phenols, 3 hydrocarbons, 3 amines, 2 aldehydes, 5 ethers, and 5 other components. We used three different types of extraction fibers to extract the VOCs because of their different molecular polarity. Among the fibers, the $85-\mu \mathrm{m}$ PA fiber extracted most kinds of VOCs (38 different compounds) and with higher probability. The largest number of possible VOCs (62 different compounds) was obtained from the 48hFL. As shown in Table 1, the content and number of each class did not show correlation with fermentation duration. The trend in the dynamic total peak area was as follows: during the initial stage, the total peak area of all possible VOCs rose to 5004596 in the $12 \mathrm{hFL}$ and decreased to 4620461 in the $24 \mathrm{hFL}$; subsequently, the peak area sharply increased to 11527435 in the $36 \mathrm{hFL}$ and reached its peak, 19971460, in the $48 \mathrm{hFL}$, after which it gradually declined in the second half of the fermentation period $(48 \mathrm{hFL}-96 \mathrm{hFL})$. Moreover, there was no significant difference $(P>0.05)$ in the amount of total possible VOCs between the $12 \mathrm{hFL}$ and $24 \mathrm{hFL}$, and between the $72 \mathrm{hFL}$ and 84hFL.

Alcohols and ketones were the two dominant classes of VOCs produced by B. subtilis CF-3, amounting to 33 different compounds. In total, 15 kinds of alcohols were identified in this study. The number of volatilized alcohols was constant at approximately 13 kinds in all fermentation liquids, regardless of fermentation duration. The relative content of alcohols was $15.03 \%$ in the $12 \mathrm{hFL}$, and it gradually increased to the $60 \mathrm{hFL}$, when it peaked at $24.41 \%$; afterwards, it gradually decreased. During the whole fermentation period, 18 ketones were identified. Fourteen were identified in the $12 \mathrm{hFL}$, after which the number declined and reached the minimum (9 different ketones) in the $36 \mathrm{hFL}$. However, the number of ketones rapidly rose after the $36 \mathrm{hFL}$ and peaked at 15 in the $48 \mathrm{hFL}$, after which it gradually declined. At first, the relative content of ketones was $22.54 \%$ in the $12 \mathrm{hFL}$ and gradually decreased, reaching $10.56 \%$ in the $48 \mathrm{hFL}$. Afterwards, the content gradually increased until it reached $16.55 \%$ in the $84 \mathrm{hFL}$; in the $96 \mathrm{hFL}$, it dropped to the minimum of $7.40 \%$. Furthermore, 10 acids were identified in this study. In the early stage, the number of identified acids was about 5, after which the highest number of different volatilized acids (9 kinds) was identified in the 48hFL. In the mid and late fermentation periods, the number of different acids decreased. In the 12hFL and $48 \mathrm{hFL}$, but not the $36 \mathrm{hFL}$, the relative content of acids was relatively high. Subsequently, the relative content decreased. Among the VOCs, 5 identified compounds were phenols. The number of volatilized phenols was constant at about 4 kinds during the entire fermentation. The highest relative content of phenols (13.71\%) was identified in the $24 \mathrm{hFL}$. Furthermore, all fermentation liquids, regardless of fermentation duration, contained only two volatilized aldehydes, benzaldehyde and 3-methylbutanal. The relative content of aldehydes increased at first and peaked in the $24 \mathrm{hFL}$ at $7.73 \%$, after which it gradually decreased. Of these two aldehydes, benzaldehyde occupied the larger portion. In addition, 2 unsorted compounds were identified in this study: methoxy-phenyl-oxime and benzothiazole. As the fermentation progressed, the relative content of methoxyphenyl-oxime increased, peaking at $58.68 \%$ in the $96 \mathrm{hFL}$, wherein it occupied the largest portion of unsorted compounds. Anisole, as the ether most commonly identified in this study, occupied a large proportion among the VOCs and was mostly produced in the $60 \mathrm{hFL}$. Finally, the major VOCs produced by $\mathrm{CF}-3$ that were identified at different fermentation times are presented in Table 2: most of the major VOCs, i.e., $(S)-1$ octanol, benzoic acid, 2,4-di-tert-butylthiophenol, benzaldehyde, and benzothiazole, were already produced by the $24 \mathrm{hFL}$. As the fermentation progressed, the quantity of the major VOCs gradually decreased.

The rates of M. fructicola and C. gloeosporioides inhibition by the VOCs produced by B. subtilis CF-3 were measured at different fermentation times and listed in Table 3. The inhibition rate of M. fructicola reached its peak of $73.46 \pm$ $3.88 \%$ by $24 \mathrm{hFL}$, and there was a subsequent overall declining trend in the inhibition that included one rebound by 96hFL. The inhibition rate of C. gloeosporioides first reached its peak of $63.63 \pm 4.69 \%$ by $24 \mathrm{hFL}$, then decreased gradually except aside from a rebound by 60hFL. Although the most VOCs were identified in $48 \mathrm{hFL}$, the VOCs from $24 \mathrm{hFL}$ showed the strongest inhibitory effects among all the liquids on both fungal pathogens. The GC-MS chromatograms of VOCs produced by $24 \mathrm{hFL}$ are shown in Figure 3.

TABLE 3 | Rates of M. fructicola and C. gloeosporioides inhibition by VOCs produced by B. subtilis CF-3 at different fermentation times.

\begin{tabular}{lcccccccc}
\hline Fungal pathogen & \multicolumn{7}{c}{ Inhibition rate (\%) on fungal pathogens } \\
\cline { 2 - 5 } & $\mathbf{1 2 h F L}$ & $\mathbf{2 4 h F L}$ & $\mathbf{3 6 h F L}$ & $\mathbf{4 8 h F L}$ & $\mathbf{6 0 h F L}$ & $\mathbf{7 2 h F L}$ & $\mathbf{8 4 h F L}$ & $\mathbf{9 6 h F L}$ \\
\hline M. fructicola & $69.78 \pm 3.17 \mathrm{ab}$ & $73.46 \pm 3.88 \mathrm{a}$ & $64.65 \pm 4.13 \mathrm{bc}$ & $59.94 \pm 5.54 \mathrm{c}$ & $51.50 \pm 3.52 \mathrm{~d}$ & $46.85 \pm 4.42 \mathrm{~d}$ & $33.43 \pm 5.05 \mathrm{e}$ & $38.48 \pm 4.68 \mathrm{e}$ \\
C. gloeosporioides & $59.11 \pm 5.39 \mathrm{a}$ & $63.63 \pm 4.69 \mathrm{a}$ & $57.30 \pm 4.10 \mathrm{a}$ & $56.64 \pm 3.81 \mathrm{a}$ & $59.88 \pm 3.98 \mathrm{a}$ & $43.11 \pm 2.33 \mathrm{~b}$ & $42.50 \pm 5.11 \mathrm{~b}$ & $22.27 \pm 4.08 \mathrm{c}$
\end{tabular}

The different letters represent significant differences $(P<0.05)$ in inhibition rates between the different $B$. subtilis $C F-3$ fermentation liquids on the same fungal pathogen. 
Moreover, correlations between the peak area of VOCs produced by $B$. subtilis $\mathrm{CF}-3$ and the inhibition rates on M. fructicola and C. gloeosporioides were analyzed by bivariate correlation analysis. The key compounds that had significant $(P<0.05)$ positive correlation with the inhibition rate are listed in Table 4. We observed significant $(P<0.05)$ positive correlations between the amounts of produced 2,4di-tert-butylphenol, 1-octanol, and benzothiazole and the inhibition rates against both M. fructicola and C. gloeosporioides. Additionally, benzoic acid and benzaldehyde were significantly $(P<0.05)$ positively correlated with the inhibition rate against $M$. fructicola, and anisole and 3-methylbutanal were significantly $(P<0.05)$ positively correlated with the inhibition rate against $C$. gloeosporioides. Those VOCs that exhibited significant $(P<0.05)$ positive correlations with inhibition rates were chosen as target VOCs in the following experiment.

\section{Inhibitory Effects of the Identified VOCs on Fungal Pathogens Inhibitory Effects of Single Identified VOCs on Fungal Pathogens in Vitro}

The inhibition rate of single identified VOCs on M. fructicola and C. gloeosporioides after different dilution times is shown in Figure 4, while the $\mathrm{EC}_{50}$ of the VOCs are shown in Table 5. The $\mathrm{EC}_{50}$ values of 2,4-di-tert-butylphenol and 1-octanol on the two selected fungal pathogens were reported previously (Gao H. Y. et al., 2017). Among the selected compounds, 1-octanol showed the strongest inhibitory effect against $M$. fructicola, and its $\mathrm{EC}_{50}$ was $4.77 \times 10^{-5} \mathrm{~mol} / \mathrm{L}$. Furthermore, 2,4di-tert-butylthiophenol $\left(\mathrm{EC}_{50}=9.90 \times 10^{-4} \mathrm{~mol} / \mathrm{L}\right)$ and benzaldehyde $\left(\mathrm{EC}_{50}=6.70 \times 10^{-4} \mathrm{~mol} / \mathrm{L}\right)$ exhibited strong inhibitory effects as well. Additionally, 3-methylbutanal showed the strongest inhibitory effect on C. gloeosporioides, with an $\mathrm{EC}_{50}$ of $7.67 \times 10^{-3} \mathrm{~mol} / \mathrm{L}$, and 2,4-di-tert-butylthiophenol showed a strong inhibitory effect $\left(\mathrm{EC}_{50}=1.26 \times 10^{-2} \mathrm{~mol} / \mathrm{L}\right)$ as well; the remaining compounds exhibited relatively weak inhibitory effects.

\section{Inhibitory Effects of Single Identified VOCs and the 24hFL From B. subtilis CF-3 on Fungal Pathogens in Vivo}

In the present study, two indexes, the mycelial inhibition rate and the healthy fruit rate, were evaluated on both peaches and litchi fruit (Figures 5, 6). In peaches, benzothiazole treatment showed the strongest inhibitory effect on the mycelial growth among all treatments (Figure 7A). Moreover, benzothiazole treatment significantly increased the healthy fruit rate (Figure $7 \mathbf{B}$ ), which was still at approximately $20 \%$ after 5 -day storage at $25^{\circ} \mathrm{C}$, while no fruit remained healthy in the other treatment groups after 5 days. The 24hFL from B. subtilis CF-3 showed relatively strong inhibitory effects in vivo, which were inferior only to those of benzothiazole. In litchi fruit, all compounds showed inhibitory effects on pathogen mycelial growth, and, among the compounds, anisole showed the weakest inhibitory effect (Figure 7C). Although there was no significant difference
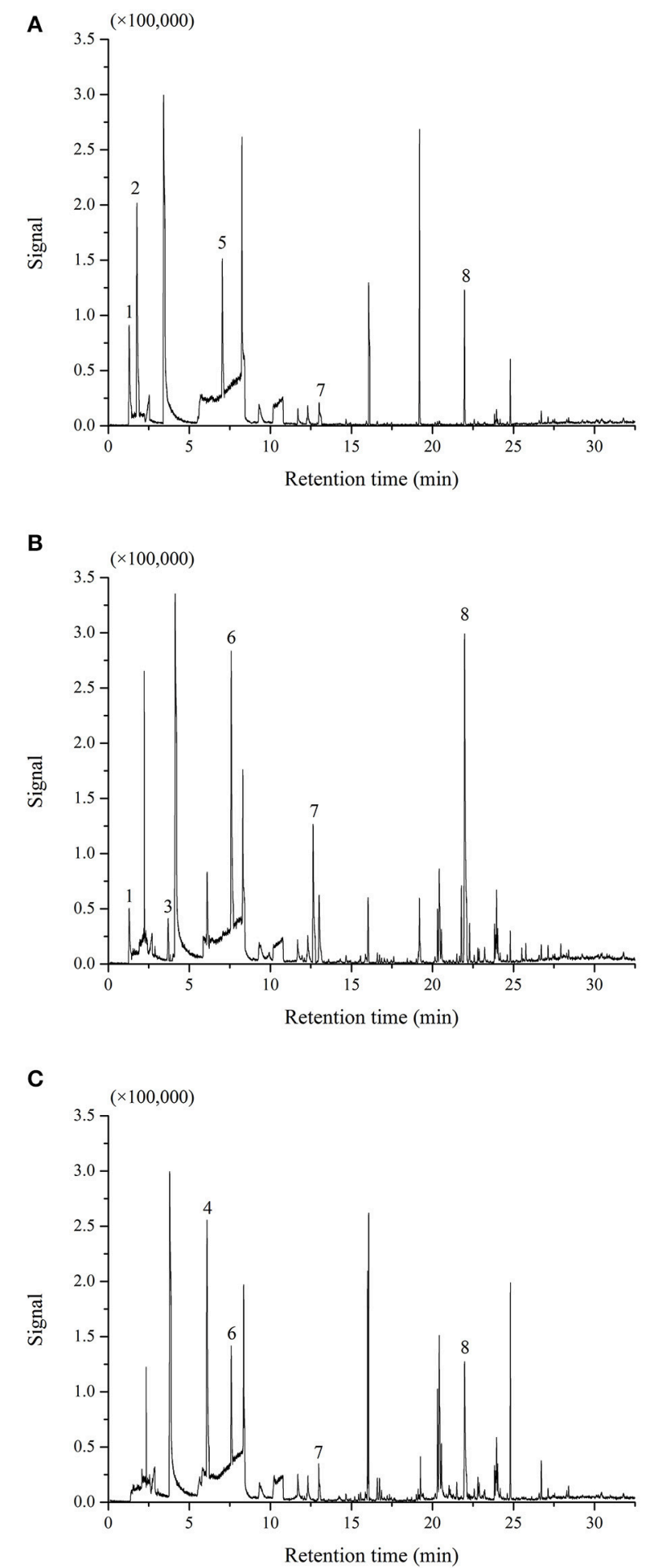

FIGURE 3 | Chromatograms of VOCs produced by the 24-h fermentation liquid (24hFL) extracted by $7-\mu \mathrm{m}$ PDMS (A), 85- $\mu \mathrm{m}$ PA (B), and $100-\mu \mathrm{m}$ PDMS (C). The main VOCs were noted as (1) (S)-1-octanol, (2) benzaldehyde, (3) 3-methylbutanal, (4) benzoic acid, (5) methoxy-phenyl-oxime, (6) anisole, (7) benzothiazole, and (8) 2,4-di-tert-butylthiophenol. The remaining peaks represent other minor VOCs or the fibers and atmosphere. 
TABLE 4 | The Pearson correlation coefficients of single compounds whose levels had significant positive correlations $(P<0.05)$ with the rates of $M$. fructicola and C. gloeosporioides inhibition.

\begin{tabular}{|c|c|c|c|c|}
\hline \multirow[t]{2}{*}{ Volatile compound } & \multicolumn{2}{|c|}{$\begin{array}{l}\text { With dynamic rate } \\
\text { of } M \text {. fructicola } \\
\text { inhibition }\end{array}$} & \multicolumn{2}{|c|}{$\begin{array}{c}\text { With dynamic rate of } \\
\text { C. gloeosporioides } \\
\text { inhibition }\end{array}$} \\
\hline & $\begin{array}{l}\text { Pearson } \\
\text { correlation } \\
\text { coefficient }\end{array}$ & $P$-value & $\begin{array}{l}\text { Pearson } \\
\text { correlation } \\
\text { coefficient }\end{array}$ & $P$-value \\
\hline 2,4-di-tert-butylphenol & 0.817 & 0.013 & 0.748 & 0.033 \\
\hline 1-octanol & 0.799 & 0.017 & 0.730 & 0.040 \\
\hline Benzothiazole & 0.793 & 0.019 & 0.786 & 0.021 \\
\hline Benzoic acid & 0.782 & 0.022 & - & ns \\
\hline Benzaldehyde & 0.759 & 0.029 & - & ns \\
\hline Anisole & - & ns & 0.712 & 0.048 \\
\hline 3-methylbutanal & - & ns & 0.795 & 0.018 \\
\hline
\end{tabular}

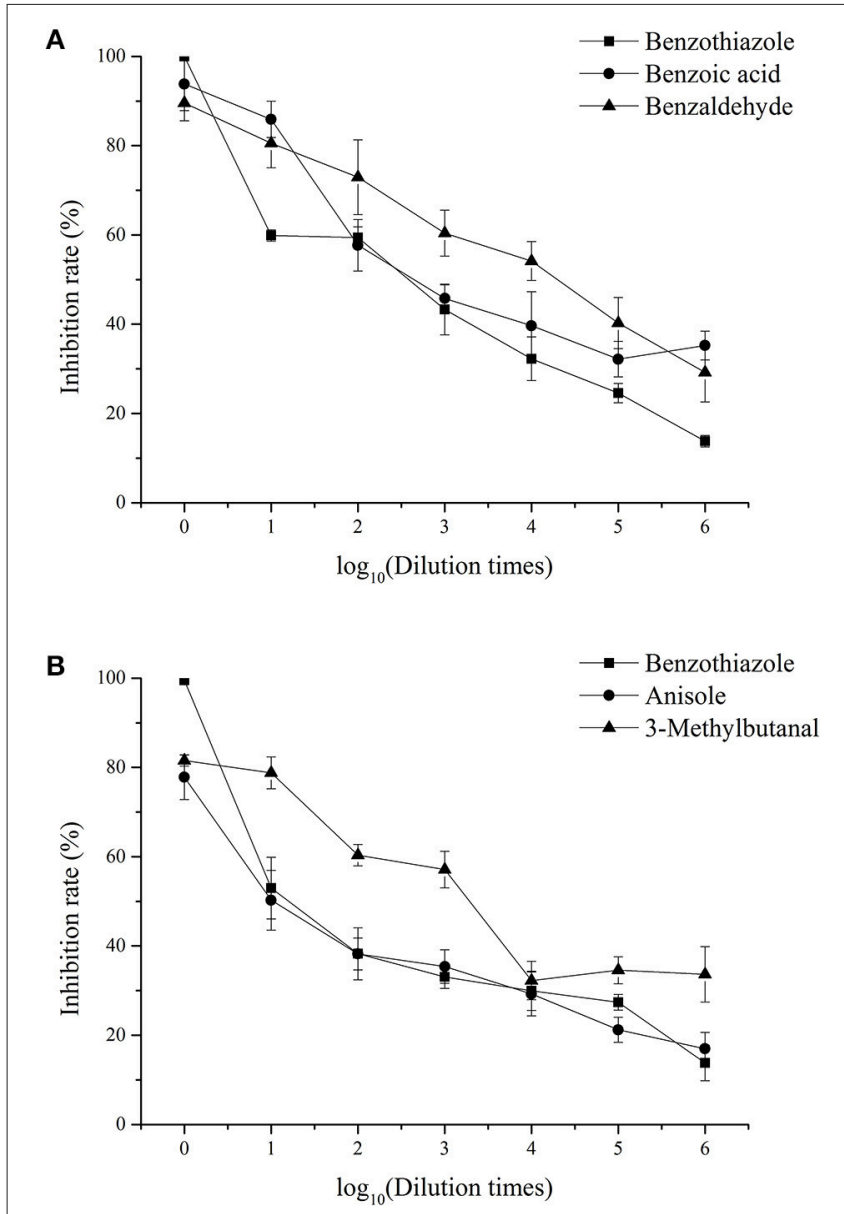

FIGURE 4 | Inhibitory effects of single identified VOCs on M. fructicola (A) and C. gloeosporioides (B) after different dilution times in vitro. Each spot represents the mean value from three independent experiments, and the vertical bars represent the standard errors of the means for each treatment.
TABLE 5 | EC F0 $_{50}$ of different VOCs for inhibiting the mycelial growth of M. fructicola and C. gloeosporioides.

\begin{tabular}{lcc}
\hline Volatile compound & M. fructicola & C. gloeosporioides \\
\hline & EC $_{\mathbf{5 0}}$ ( $\left.\mathbf{m o l} / \mathbf{L}\right)$ & EC $_{\mathbf{5 0}}$ ( $\left.\mathbf{m o l} / \mathbf{L}\right)$ \\
\hline Benzothiazole & $2.29 \times 10^{-2}$ & 0.36 \\
Benzoic acid & $1.46 \times 10^{-3}$ & $\mathrm{nt}$ \\
Benzaldehyde & $6.70 \times 10^{-4}$ & $\mathrm{nt}$ \\
Anisole & $\mathrm{nt}$ & 0.59 \\
3-methylbutanal & $\mathrm{nt}$ & $7.67 \times 10^{-3}$ \\
\hline "nt" means not tested in this study. & &
\end{tabular}

between the other treatments, benzothiazole treatment showed the strongest relative inhibitory effect. After storage at $25^{\circ} \mathrm{C}$ for 5 days, no fruit remained healthy in any of the treatment groups (Figure 7D).

\section{DISCUSSION}

Considering the risks the drug resistance of fungal pathogens and environmental pollution caused by the abuse of chemical fungicides present to human health, the need for both environmentally friendly and more effective methods for controlling fungal diseases in plants is increasing rapidly. Biological control has been widely regarded as a potential substitute for chemical control because of its high efficiency and environmental safety, and $B$. subtilis has been widely studied in this context. The main antifungal substances secreted by $B$. subtilis are enzymes and antibiotic lipopeptides, including surfactin, iturin, and fengycin (Ongena et al., 2007; Wang and Yeh, 2008; Liu et al., 2011; Torres et al., 2016). However, recent research has indicated that VOCs produced by $B$. subtilis, its primary and secondary metabolites, also have strong antifungal effects and application potential (Leelasuphakul et al., 2008; Arrebola et al., 2010; Zheng et al., 2013).

In a previous study, the VOCs produced by the B. subtilis CF3 strain were isolated and identified from fermented bean curd (Gao et al., 2016). The results of the present study indicate that the VOCs produced by B. subtilis CF- 3 have inhibitory effects on several common fungal pathogens in vitro. To clarify whether VOCs from the CFF or BS also have inhibitory effects on the tested fungal pathogens, the inhibition rates of the CFF and BS were also evaluated. The results demonstrated that the inhibitory effects of VOCs from the studied liquids differed depending on the given pathogen. This indicates that optimal treatments for different fungal pathogen infections will be different. Moreover, although the CFF and BS were separated from the $24 \mathrm{hFL}$, the sum of the inhibition rates of these two component liquids did not equal the inhibition rate of the $24 \mathrm{hFL}$, indicating that some interactions between the VOCs and the CF- 3 strain that enhance the inhibition of fungal pathogens may exist. Although the $24 \mathrm{hFL}$ did not contain the majority of the VOCs, the VOCs from the $24 \mathrm{hFL}$ showed the strongest inhibitory effects among all fermentation liquids on both M. fructicola and C. gloeosporioides. 


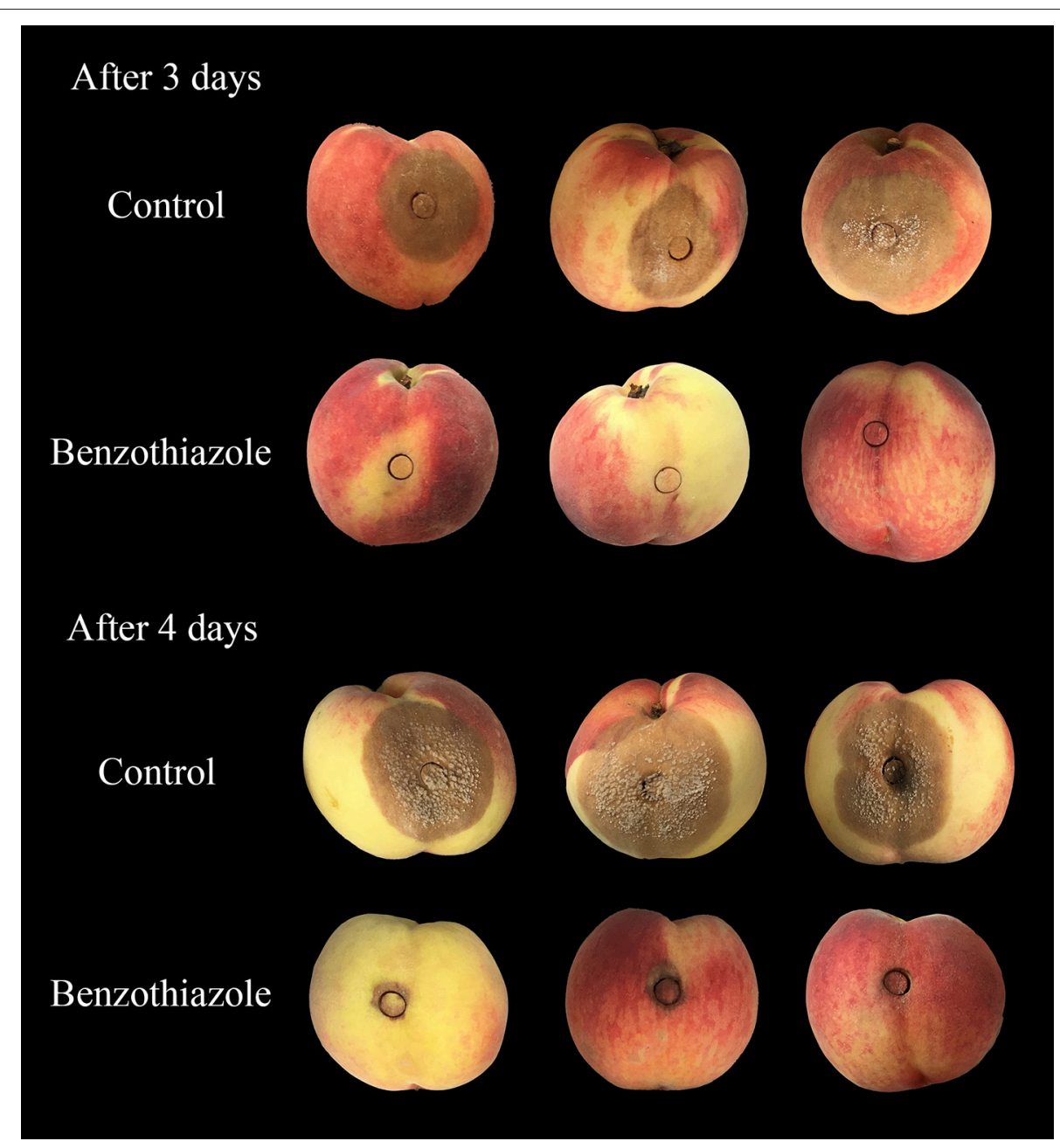

FIGURE 5 | Effects of benzothiazole on M. fructicola in vivo after 3 and 4 days.

The 24hFL contained more key inhibitory VOCs like (S)-1octanol, benzoic acid, 2,4-di-tert-butylthiophenol, benzaldehyde, and benzothiazole (Table 2), and it showed a significant positive correlation with the inhibition rates (Table 4) compared to the other fermentation liquids.

Previous studies have classified the common VOCs secreted by microorganisms into alcohols, aldehydes, hydrocarbons, esters, ketones, organic acids, and other compounds (Wang et al., 2016). In the present study, three different extraction fibers were used, and the $85-\mu \mathrm{m}$ PA fibers were shown to be optimal for extraction, since they extracted the most VOCs (38 different compounds) with a higher probability, in conformance with our previous study (Gao H. Y. et al., 2017). Based on the bivariate correlation analysis, the quantities of three VOCs, 2,4-di-tertbutylphenol, 1-octanol, and benzothiazole, showed a significant $(P<0.05)$ correlation with the rates of $M$. fructicola and C. gloeosporioides inhibition. Previous studies have reported that 2,4-di-tert-butylphenol has antifungal abilities against several fungi such as Aspergillus niger and Penicillium chrysogenum
(Varsha et al., 2015; Belghit et al., 2016). Additionally, 2,4-ditert-butylphenol, as a VOC produced by Pseudomonas monteilii PsF84, has been shown to inhibit the spore germination and hyphal growth of Fusarium oxysporum (Dharni et al., 2014). Our HS-SPME-GC-MS results showed relatively high 2,4-ditert-butylphenol content among the VOCs, its relative content in the $24 \mathrm{hFL}$ being $12.32 \%$. The calculation of $\mathrm{EC}_{50}$ also demonstrated that 2,4-di-tert-butylphenol had relatively strong inhibitory activity against the two selected fungal pathogens: 9.90 $\times 10^{-4} \mathrm{~mol} / \mathrm{L}$ for $M$. fructicola and $1.26 \times 10^{-2} \mathrm{~mol} / \mathrm{L}$ for C. gloeosporioides (Gao H. Y. et al., 2017). These high values might explain why the $24 \mathrm{hFL}$ from B. subtilis CF-3 showed the strongest inhibitory effect despite not containing the majority of the VOCs. Moreover, in a previous study, 2,4-di-tert-butylphenol also showed a relatively strong inhibitory effect on mycelial growth of $M$. fructicola in an in vivo experiment, in which its inhibition rate remained at about $40 \%$ after 5 -day incubation (Gao H. Y. et al., 2017). These results demonstrated that 2,4di-tert-butylphenol, which was present at high levels in the 


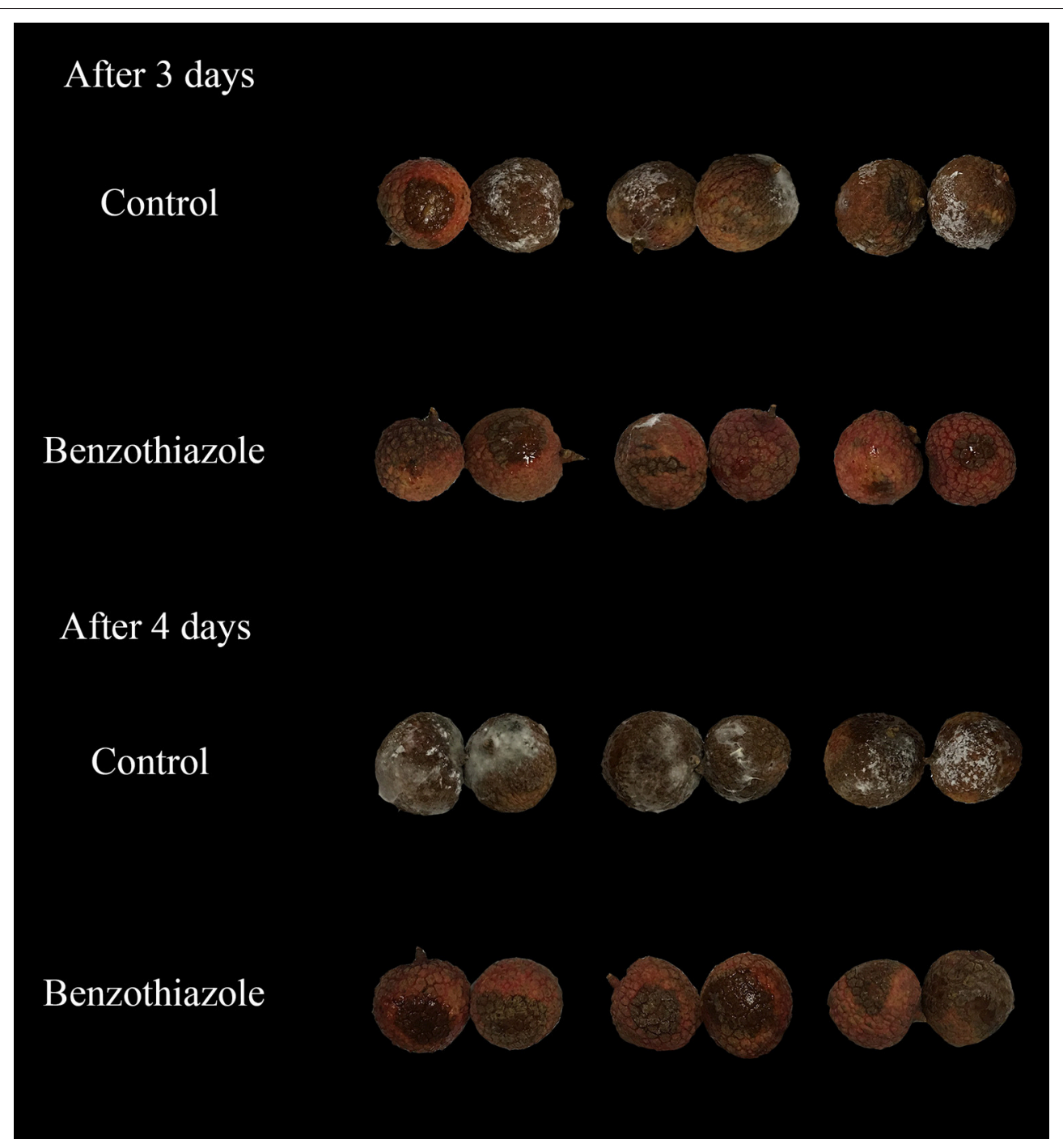

FIGURE 6 | Effects of benzothiazole on C. gloeosporioides in vivo after 3 and 4 days.

fermentation liquids and showed strong inhibitory effects, is a key antifungal VOC produced by $B$. subtilis CF-3.

In addition to 2,4-di-tert-butylphenol, 1-octanol and benzothiazole also played important roles in fungal inhibition. 1-Octanol has been demonstrated to completely inhibit spore germination of Penicillium camemberti at low concentrations (Gillot et al., 2016). Benzothiazole and its derivatives are regarded as some of the most useful heterocyclic compounds and are widely used in medicinal chemistry for their effects (Keri et al., 2015). Benzothiazole showed the strongest inhibitory effect on both fungal pathogens and increased the healthy fruit rate in both peaches and litchi fruit in the in vivo experiment. VOCs released by Bacillus velezensis ZSY-1, among which benzothiazole had a much larger relative peak area than the other compounds, were shown to exhibit significant antifungal activity against M. fructicola, and benzothiazole has been demonstrated to be a promising bioagent for controlling fungal diseases such as gray mold and early blight on tomato fruit (Gao Z. F. et al., 2017). Additionally, benzothiazole, which was also found in the VOCs produced by fungi of the Xylariaceae family in olive trees, has been shown to play a significant role in reducing the mycelial expansion of Colletotrichum acutatum in olives (Landum et al., 2016). In the present study, benzothiazole did not show the strongest inhibitory effect on mycelial growth of fungal pathogens in vitro. However, it showed the strongest inhibitory effect in vivo. The results indicate that benzothiazole, which displayed prominent inhibitory effects in vivo, especially on M. fructicola, is a key antifungal VOC produced by B. subtilis CF-3. Besides benzothiazole, other VOCs showed different inhibitory effects in in vivo and in vitro experiments. This difference may not only be due to the direct inhibition of the growth of fungal mycelia, but also due to some VOCs stimulating the fruit to activate enzymes that improve the defense against fungal infections. 3-methylbutanal showed 

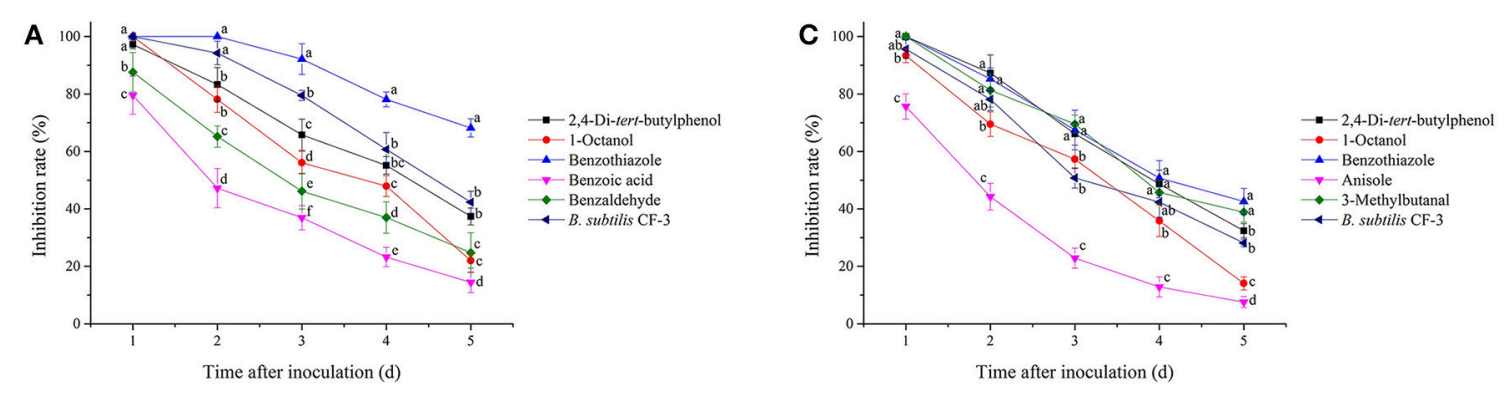

B

D
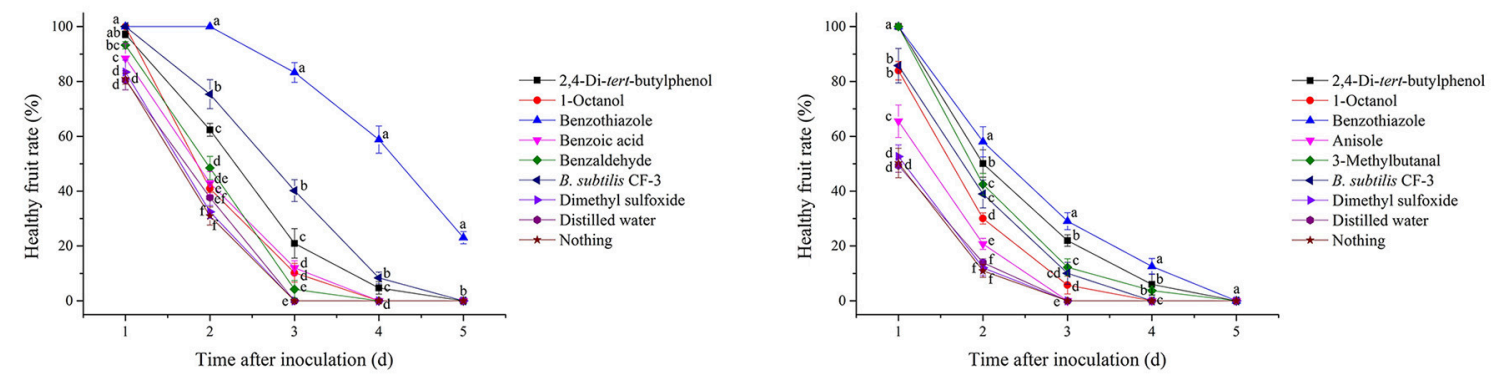

FIGURE 7 | Inhibitory effects of single identified VOCs and the 24-h fermentation liquid (24hFL) of B. subtilis CF-3 on peaches (A,B) and litchi fruit (C,D) in vivo. Two indexes were evaluated: the mycelial inhibition rate $(\mathbf{A}, \mathbf{C})$ and the healthy fruit rate $(\mathbf{B}, \mathbf{D})$. Each dot represents the mean of replicates from three independent experiments, and the vertical bars represent the standard errors of the means for each treatment. Different letters represent significant differences $(P<0.05)$ between different treatments on the same day.

strong inhibitory effects on C. gloeosporioides in both the in vivo and in vitro experiments. In addition, it reportedly had an inhibitory effect on some fungal pathogens in other studies. Isovaleraldehyde (3-methylbutanal) was identified in the essential oil obtained from Senecio graveolens (Compositae), which showed inhibitory effects on the growth of Candida albicans (Perez et al., 1999).

The results of the present study indicate that 2,4-di-tertbutylthiophenol and benzothiazole are two key inhibitory VOCs produced by $B$. subtilis CF-3. However, the mechanisms by which these two compounds inhibit the growth of $M$. fructicola and $C$. gloeosporioides in vivo and in vitro are still unclear and ought to be clarified in future studies.

\section{CONCLUSION}

The VOCs produced by B. subtilis CF-3 showed antifungal activity against several common fruit fungal pathogens. M. fructicola and C. gloeosporioides were the two most inhibited fungi. Using HS-SPME-GC-MS, 74 probable VOCs were identified during fermentation: 15 alcohols, 18 ketones, 4 pyrazines, 4 esters, 10 acids, 5 phenols, 3 hydrocarbons, 3 amines, 2 aldehydes, 5 ethers, and 5 other components. The number and levels of VOCs differed depending on the fermentation duration. Most VOCs (62 compounds) were identified in the 48hFL. Inhibition rates of the VOCs all reached their peaks in the 24hFL. Significant $(P<0.05)$ positive correlations between levels of 2,4-di-tert-butylphenol, 1-octanol, and benzothiazole and the rates of M. fructicola and C. gloeosporioides inhibition were observed. Benzoic acid and benzaldehyde levels showed significant $(P<0.05)$ positive correlations with the rates of $M$. fructicola inhibition, and anisole and 3-methylbutanal showed the same against C. gloeosporioides. Treatment with 2,4-di-tert-butylphenol showed strong inhibitory effects on both $M$. fructicola and $C$. gloeosporioides in vitro. Benzothiazole showed the strongest inhibitory effects on the mycelial extension of both M. fructicola and C. gloeosporioides in vivo, and also increased the healthy fruit rate. Our results demonstrated that 2,4-di-tert-butylthiophenol and benzothiazole are key inhibitory VOCs produced by B. subtilis CF-3. These results lay a preliminary foundation for the clarification of key biocontrol VOCs and provide a theoretical basis for improving biocontrol efficiency and application of B. subtilis strains in the biocontrol field.

\section{AUTHOR CONTRIBUTIONS}

HG, PL, XX, and WG designed the experiments. PL and XX performed the experiments. PL, XX, and QZ analyzed the data. HG and PL drafted the manuscript. All authors read and approved the final manuscript.

\section{ACKNOWLEDGMENTS}

This study was supported by the National Science-technology Support Plan Project (No. 2015BAD16B02) and National Natural Science Foundation of China (No. 31401539). This study was also 
supported by the project of Food Science Discipline Construction of Shanghai University.

The fungal strains A. alternata, B. cinerea, M. kuwatsukai, and $P$. expansum were kindly supplied by Prof. Yuanhong Wang of the College of Horticulture and Landscape, Tianjin Agricultural University. C. gloeosporioides was kindly provided by Prof.

\section{REFERENCES}

Arrebola, E., Sivakumar, D., and Korsten, L. (2010). Effect of volatile compounds produced by Bacillus strains on postharvest decay in citrus. Biol. Control 53, 122-128. doi: 10.1016/j.biocontrol.2009.11.010

Banani, H., Spadaro, D., Zhang, D., Matic, S., Garibaldi, A., and Guilin, M. L. (2015). Postharvest application of a novel chitinase cloned from Metschnikowia fructicola and overexpressed in Pichia pastoris to control brown rot of peaches. Int. J. Food Microbiol. 199, 54-61. doi: 10.1016/j.ijfoodmicro.2015.01.002

Belghit, S., Driche, E. H., Bijani, C., Zitouni, A., Sabaou, N., Badji, B., et al. (2016). Activity of 2,4-Di-tert-butylphenol produced by a strain of Streptomyces mutabilis isolated from a Saharan soil against Candida albicans and other pathogenic fungi. J. Mycol. Med. 26, 160-169. doi: 10.1016/j.mycmed.2016.03.001

Casals, C., Elmer, P. A. G., Vinas, I., Teixido, N., Sisquella, M., and Usall, J. (2012). The combination of curing with either chitosan or Bacillus subtilis CPA-8 to control brown rot infections caused by Monilinia fructicola. Postharvest Biol. Tec. 64, 126-132. doi: 10.1016/j.postharvbio.2011.06.004

Chen, H., Xiao, X., Wang, J., Wu, L., Zheng, Z., and Yu, Z. (2008). Antagonistic effects of volatiles generated by Bacillus subtilis on spore germination and hyphal growth of the plant pathogen Botrytis cinerea. Biotechnol. Lett. 30, 919-923. doi: 10.1007/s10529-007-9626-9

Dharni, S., Sanchita, Maurya, A., Samad, A., Srivastava, S. K., Sharma, A., et al. (2014). Purification, characterization, and in vitro activity of 2,4-Di-tertbutylphenol from Pseudomonas monteilii PsF84: conformational and molecular docking studies. J. Agric. Food Chem. 62, 6138-6146. doi: 10.1021/jf5001138

Fischer, J. M. M., Savi, D. C., Aluizio, R., May De Mio, L. L., and Glienke, C. (2017). Characterization of Monilinia species associated with brown rot in stone fruit in Brazil. Plant Pathol. 66, 423-436. doi: 10.1111/ppa.12578

Gao, H. Y., Xu, X. X., Dai, Y. W., and He, H. X. (2016). Isolation, identification and characterization of Bacillus subtilis CF-3, a bacterium from fermented bean curd for controlling postharvest diseases of peach fruit. Food Sci. Technol. Res. 22, 377-385. doi: 10.3136/fstr.22.377

Gao, H. Y., Xu, X. X., Zeng, Q., and Li, P. Z. (2017). Optimization of headspace Solid-phase microextraction for GC-MS analysis of volatile compounds produced by biocontrol strain Bacillus subtilis CF-3 using response surface methodology. Food Sci. Technol. Res. 23, 583-593. doi: 10.3136/fstr.23.583

Gao, Z. F., Zhang, B. J., Liu, H. P., Han, J. C., and Zhang, Y. J. (2017). Identification of endophytic Bacillus velezensis ZSY-1 strain and antifungal activity of its volatile compounds against Alternaria solani and Botrytis cinerea. Biol. Control 105, 27-39. doi: 10.1016/j.biocontrol.2016.11.007

Gillot, G., Decourcelle, N., Dauer, G., Barbier, G., Coton, E., Delmail, D., et al. (2016). 1-Octanol, a self-inhibitor of spore germination in Penicillium camemberti. Food Microbiol. 57, 1-7. doi: 10.1016/j.fm.2015.12.008

Jiang, C. M., Shi, J. L., Liu, Y. L., and Zhu, C. Y. (2014). Inhibition of Aspergillus carbonarius and fungal contamination in table grapes using Bacillus subtilis. Food Control 35, 41-48. doi: 10.1016/j.foodcont.2013.06.054

Keri, R. S., Patil, M. R., Patil, S. A., and Budagumpi, S. (2015). A comprehensive review in current developments of benzothiazole based molecules in medicinal chemistry. Eur. J. Med. Chem. 89, 207-251. doi: 10.1016/j.ejmech.2014.10.059

Landum, M. C., Felix, M. D., Alho, J., Garcia, R., Cabrita, M. J., Rei, F., et al. (2016). Antagonistic activity of fungi of Olea europaea L. against Colletotrichum acutatum. Microbiol. Res. 183, 100-108. doi: 10.1016/j.micres.2015.12.001

Leelasuphakul, W., Hemmanee, P., and Chuenchitt, S. (2008). Growth inhibitory properties of Bacillus subtilis strains and their metabolites against the green mold pathogen (Penicillium digitatum Sacc.) of citrus fruit. Postharvest Biol. Tec. 48, 113-121. doi: 10.1016/j.postharvbio.2007.09.024
Xinchun Zhang of the Chinese Academy of Tropical Agricultural Sciences Environment and Plant Protection Institute, and M. fructicola was kindly provided by Prof. Xiaoyan Zhao of the Laboratory of Agricultural Products Processing and Storage, Food Science and Engineering College, Beijing University of Agriculture.
Liu, Y., Tao, J., Yan, Y. J., Li, B., Li, H., and Li, C. (2011). Biocontrol efficiency of Bacillus subtilis SL-13 and characterization of an antifungal chitinase. Chinese J. Chem. Eng. 19, 128-134. doi: 10.1016/S1004-9541(09)60188-9

Ma, X., Wang, X. B., Cheng, J., Nie, X., Yu, X. X., Zhao, Y. T., et al. (2015). Microencapsulation of Bacillus subtilis B99-2 and its biocontrol efficiency against Rhizoctonia solani in tomato. Biol. Control 90, 34-41. doi: 10.1016/j.biocontrol.2015.05.013

Maachia, B., Rafik, E., Chérif, M., Nandal, P., Mohapatra, T., and Bernard, P. (2015). Biological control of the grapevine diseases 'grey mold' and 'powdery mildew’ by Bacillus B27 and B29 strains. Indian J. Exp. Biol. 53, 109-115.

Mari, M., Martini, C., Guidarelli, M., and Neri, F. (2012). Postharvest biocontrol of Monilinia laxa, Monilinia fructicola and Monilinia fructigena on stone fruit by two Aureobasidium pullulans strains. Biol. Control 60, 132-140. doi: 10.1016/j.biocontrol.2011.10.013

Munir, M., Amsden, B., Dixon, E., Vaillancourt, L., and Gauthier, N. A. W. (2016). Characterization of Colletotrichum species causing bitter rot of apple in Kentucky Orchards. Plant Dis. 100, 2194-2203. doi: 10.1094/PDIS-10-15-1144-RE

Ongena, M., Jourdan, E., Adam, A., Paquot, M., Brans, A., Joris, B., et al. (2007). Surfactin and fengycin lipopeptides of Bacillus subtilis as elicitors of induced systemic resistance in plants. Environ. Microbiol. 9, 1084-1090. doi: 10.1111/j.1462-2920.2006.01202.x

Perez, C., Agnese, A. M., and Cabrera, J. L. (1999). The essential oil of Senecio graveolens (Compositae): chemical composition and antimicrobial activity tests. J. Ethnopharmacol. 66, 91-96. doi: 10.1016/S0378-8741(98) 00204-9

Prusky, D. (2011). Reduction of the incidence of postharvest quality losses, and future prospects. Food Secur. 3, 463-474. doi: 10.1007/s12571-011-0147-y

Schreinemachers, P., and Tipraqsa, P. (2012). Agricultural pesticides and land use intensification in high, middle and low income countries. Food Policy 37, 616-626. doi: 10.1016/j.foodpol.2012.06.003

Senthil, R., Prabakar, K., Rajendran, L., and Karthikeyan, G. (2011). Efficacy of different biological control agents against major postharvest pathogens of grapes under room temperature storage conditions. Phytopathol. Mediterr. 50, 55-65.

Sivakumar, D., Arrebola, E., and Korsten, L. (2008). Postharvest decay control and quality retention in litchi (cv. McLean's Red) by combined application of modified atmosphere packaging and antimicrobial agents. Crop Prot. 27, 1208-1214. doi: 10.1016/j.cropro.2008.03.002

Spadoni, A., Guidarelli, M., Phillips, J., Mari, M., and Wisniewski, M. (2015). Transcriptional profiling of apple fruit in response to heat treatment: involvement of a defense response during Penicillium expansum infection. Postharvest Biol. Technol. 101, 37-48. doi: 10.1016/j.postharvbio.2014. 10.009

Torres, M. J., Brandan, C. P., Petroselli, G., Erra-Balsells, R., and Audisio, M. C. (2016). Antagonistic effects of Bacillus subtilis subsp subtilis and $B$. amyloliquefaciens against Macrophomina phaseolina: SEM study of fungal changes and UV-MALDI-TOF MS analysis of their bioactive compounds. Microbiol. Res. 182, 31-39. doi: 10.1016/j.micres.2015.09.005

Ugolini, L., Martini, C., Lazzeri, L., D’Avino, L., and Mari, M. (2014). Control of postharvest grey mould (Botrytis cinerea Per.: Fr.) on strawberries by glucosinolate-derived allyl-isothiocyanate treatments. Postharvest Biol. Technol. 90, 34-39. doi: 10.1016/j.postharvbio.2013.12.002

Varsha, K. K., Devendra, L., Shilpa, G., Priya, S., Pandey, A., and Nampoothiri, K. M. (2015). 2,4-Di-tert-butyl phenol as the antifungal, antioxidant bioactive purified from a newly isolated Lactococcus sp. Int. J. Food Microbiol. 211, 44-50. doi: 10.1016/j.ijfoodmicro.2015.06.025 
Wang, C. J., and Liu, Z. Q. (2007). Foliar uptake of pesticides present status and future challenge. Pestic. Biochem. Physiol. 87, 1-8. doi: $10.1016 /$ j.pestbp.2006.04.004

Wang, J., Xia, X. M., Wang, H. Y., Li, P. P., and Wang, K. Y. (2013). Inhibitory effect of lactoferrin against gray mould on tomato plants caused by Botrytis cinerea and possible mechanisms of action. Int. J. Food Microbiol. 161, 151-157. doi: 10.1016/j.ijfoodmicro.2012.11.025

Wang, S. L., and Yeh, P. Y. (2008). Purification and characterization of a chitosanase from a nattokinase producing strain Bacillus subtilis TKU007. Process Biochem. 43, 132-138. doi: 10.1016/j.procbio.2007.11.002

Wang, Y., Li, Y. X., Yang, J. L., Ruan, J., and Sun, C. J. (2016). Microbial volatile organic compounds and their application in microorganism identification in foodstuff. Trac-Trends Anal. Chem. 78, 1-16. doi: 10.1016/j.trac.2015.08.010

Xu, C., Wang, C. S., Ju, L. L., Zhang, R., Biggs, A. R., Tanaka, E., et al. (2015). Multiple locus genealogies and phenotypic characters reappraise the causal agents of apple ring rot in China. Fungal Divers. 71, 215-231. doi: 10.1007/s13225-014-0306-5

Yan, J. Q., Yuan, S. Z., Wang, C. Y., Ding, X. Y., Cao, J. K., and Jiang, W. B. (2015). Enhanced resistance of jujube (Zizyphus jujuba Mill. cv. Dongzao) fruit against postharvest Alternaria rot by beta-aminobutyric acid dipping. Sci. Hortic. 186, 108-114. doi: 10.1016/j.scienta.2015.02.018
Zhang, Y. Y., Zeng, L. Z., Yang, J. L., Zheng, X. D., and Yu, T. (2015). 6-Benzylaminopurine inhibits growth of Monilinia fructicola and induces defense-related mechanism in peach fruit. Food Chem. 187, 210-217. doi: 10.1016/j.foodchem.2015. 04.100

Zheng, M., Shi, J. Y., Shi, J., Wang, Q. G., and Li, Y. H. (2013). Antimicrobial effects of volatiles produced by two antagonistic Bacillus strains on the anthracnose pathogen in postharvest mangos. Biol. Control 65, 200-206. doi: 10.1016/j.biocontrol.2013.02.004

Conflict of Interest Statement: The authors declare that the research was conducted in the absence of any commercial or financial relationships that could be construed as a potential conflict of interest.

Copyright (c) $2018 \mathrm{Gao}, \mathrm{Li}, \mathrm{Xu}$, Zeng and Guan. This is an open-access article distributed under the terms of the Creative Commons Attribution License (CC $B Y)$. The use, distribution or reproduction in other forums is permitted, provided the original author(s) and the copyright owner are credited and that the original publication in this journal is cited, in accordance with accepted academic practice. No use, distribution or reproduction is permitted which does not comply with these terms. 